\title{
Clinical Effects of Brown Seaweed, Undaria pinnatifida (wakame), on Blood Pressure in Hypertensive Subjects
}

\author{
Yoshiya Hata, ${ }^{1, *}$ Kumiko NaKAJIMA, ${ }^{1}$ Jun-ichi UCHIDA, ${ }^{1}$ \\ Hidemasa HIDAKA, ${ }^{2}$ and Takahisa NAKANO ${ }^{3}$ \\ ${ }^{1}$ Department of Geriatric Medicine, Kyorin University School of Medicine, Tokyo \\ 181-8611, and Vascular Science Laboratory, Setagaya-ku, Tokyo 156-0043, Japan \\ ${ }^{2}$ Department of Nutrition, Tokiwa University, Mito 310-8585, Japan \\ ${ }^{3}$ Riken Vitamin Co., Ltd., Tokyo 101-8370, Japan
}

(Received February 23, 2001)

\begin{abstract}
Summary This was conducted to examine the effects of brown seaweed (wakame) on blood pressure and serum biochemical parameters in hypertensive subjects. Of the 37 elderly out-patients with hypertension who started the study, 36 of them completed it. This study was a randomly assigned, case-controlled one. Nineteen patients received a daily dose of $5 \mathrm{~g}$ of dried wakame powder packed in 12 capsules. Eighteen gendermatched subjects with age difference \pm 2 years, and starting time of participation within \pm 2 weeks, were selected as the control group. Patients visited the clinic every 4 weeks. The observation period was 8 weeks. In the wakame group, the average amount of wakame ingested was $3.3 \mathrm{~g}$. The systolic blood pressure (SBP) in this group dropped $13 \mathrm{mmHg}$ below the baseline $(p<0.01)$ after 4 weeks, and $8 \mathrm{mmHg}(p<0.05)$ after 8 weeks. The diastolic blood pressure (DBP) decreased by $9 \mathrm{mmHg}(p<$ $0.01)$ after 4 weeks and by $8 \mathrm{mmHg}(p<0.05)$ after 8 weeks. In the control group, no significant changes were seen in either SBP or DBP. However, the differences in reduction in SBP and DBP were significant between the wakame and control groups. Regarding clinical chemistry data, hypercholesterolemia in the wakame group decreased by $8 \%$ after 4 weeks. No other abnormal changes were observed in either group. We conclude that wakame has beneficial effects as a supplemental regimen in the treatment of hypertension.
\end{abstract}

Key Words: seaweed, wakame, hypertension, dietary treatment

\footnotetext{
* To whom correspondence should be addressed. Vascular Science Laboratory \# 405, 1-38-19 Matsubara, Setagaya-ku, Tokyo 156-0043, Japan (Tel: +81-3-5301-0655; Fax: +81-3-53010656; E-mail: yoshiyaht@aol.com).
} 
Seaweed is a popular traditional foodstuff in Japan. Among the seaweeds, Undaria pinnatifida (wakame; wa-ka-me) is the most widely eaten brown seaweed. It is usually marketed in dried or salted form for long-term preservation. In daily cooking, it is softened and desalted in water before use, and served in salads, or used as additives to soup or noodles, and as a garnish.

Seaweed is known to contain large quantities of soluble dietary fibers, and the brown seaweed wakame is in particular rich in a polysaccharide group known as alginates, which are known to have many physiological effects on blood pressure, serum lipids, blood glucose and insulin. Moreover, wakame is rich in various kinds of minerals. It is also abundant in n-3 polyunsaturated fatty acids, which have anti-thrombotic, anti-hyperlipidemic, and anti-allergic actions.

Yamori et al. reported that alginates showed anti-hypertensive effects on stroke-prone spontaneously hypertensive rats (SHRSP) [1]. Similar alginate effects were reported in a clinical study [2]. Tsuji et al. demonstrated that alginates also decreased the elevated serum cholesterol levels in experimental animals [3], and Torsdottir et al. showed improvement by its use in the control of diabetes mellitus [4].

Recent studies have confirmed the usefulness of non-drug treatment for hypertension by the intake of such foods as sour milk [5], garlic [6], cell wall components of lactobacillus [7], immune milk [8], fish oil [9], and antioxidants [10].

These findings prompted us to test the multifaceted action of wakame on blood pressure and other metabolic disorders in hypertensive patients, whose lives are often complicated by a cluster of life style-related disorders like hyperlipidemias, glucose intolerance, and hyperuricemia. These life-style related disorders, including hypertension, constitute risk factors for atherosclerosis. Therefore, amelioration of these disorders by daily use of a non-drug regimen of wakame would be of great significance in the prevention and treatment of atherosclerotic vascular disease.

\section{SUBJECTS AND METHODS}

Subjects. A total of 37 hypertensive patients with a mean age of 71 years (ranging from 40 and 86 years) were investigated. Among them, 26 were under treatment with various hypotensive drugs, and the rest were receiving some drug(s) for life style-related disease(s) at the out-patient clinic of Kyorin University Hospital. They were chosen for the trial because their blood pressure was occasionally higher than $150 \mathrm{mmHg}$ systolic and/or $90 \mathrm{mmHg}$ diastolic, even under salt restriction and anti-hypertensive medication. Eighteen patients were randomly assigned to the wakame supplement group, while the remaining 18 were chosen for the case-controlled group in terms of matching gender, age difference within \pm 2 years, and difference within \pm 2 weeks in enrollment date in the study. This study was conducted in accordance with the Helsinki Declaration of Human Rights, and 
all the patients gave informed consent to participate in the study.

Wakame supplement. The wakame supplement was prepared in the form of a dried powder after extensive desalinization, and $420 \mathrm{mg}$ of the wakame powder was packed in each capsule of \#1 size. The wakame preparation was a gift from Riken Food Co. Ltd. (Miyagi, Japan). The composition of the wakame powder is shown in Table 1. It contained large quantities of dietary fiber (about 53\% by weight), most of which was alginates. Calcium and magnesium made up more than $1 \%$ of the weight.

Study design. This was a randomly assigned, case-controlled study. However, we could not use a placebo in the control group for the reasons described later.

At entry, anthropometric measurements were made for body height, body weight, and body mass index. Blood pressure measurement and clinical biochemistry were done multiple times over a 4 -week period before treatment, and mean values were used as baseline values. The patients assigned to the treatment group received $5 \mathrm{~g}$ of dry powdered wakame packed in 12 capsules, which were taken daily in 3 divided doses with meals. The study lasted 8 weeks, during which blood pressure and clinical chemistry were examined every 4 weeks. The doses and types of anti-hypertensive or other previously prescribed drugs were not changed during the study period. Compliance was monitored by interviewing the patients at each hospital visit.

Blood pressure measurements and clinical chemistry. At each hospital visit, the patients were asked about their health condition, including compliance for prescribed drug(s) and the wakame supplement. Body weight was checked with the patient wearing indoor clothing but no shoes. After the physical examination, blood pressure (BP) was measured between 0900 and 1000 am on the right arm with a random zero sphygmomanometer (BP-203 RV-II; Nippon Colin Co, Tokyo) with the patient in the sitting position after at least a 5 min rest. All BP measurements were conducted by one registered nurse who was blind to the treatment assignments. Then, blood samples were taken by a registered technician. Blood cell counting and clinical chemistry were performed at the clinical laboratory of the hospital.

Table 1. Composition of dry wakame $(100 \mathrm{~g})$.

\begin{tabular}{lr}
\hline Protein $(\mathrm{g})$ & 20.9 \\
Lipid $(\mathrm{g})$ & 1.4 \\
Dietry Fiber $(\mathrm{g})$ & 53.2 \\
Ash $(\mathrm{g})$ & 14.7 \\
Sodium $(\mathrm{g})$ & 2.54 \\
Calcium $(\mathrm{g})$ & 1.36 \\
Magnesium $(\mathrm{g})$ & 1.34 \\
Iron $(\mathrm{mg})$ & 10.7 \\
Zinc $(\mathrm{mg})$ & 2 \\
Copper $(\mu \mathrm{g})$ & 130 \\
\hline
\end{tabular}

Vol. 30, 2001 
Statistical analysis. All values were expressed as means \pm SE. Statistical significance of changes in values from baseline levels was tested by the paired $t$-test. Student's $t$-test was used to check for statistical differences in blood pressure changes between the wakame and control groups. The chi-square test was used for comparison of the clinical backgrounds and the type and number of drugs taken between the 2 groups. Statistical significance was considered to be at $p<0.05$ on two tail test. Statistical analyses were performed by using the computer program SPSS (SPSS Inc., Chicago, IL).

\section{RESULTS}

\section{Fixation of subjects in the study}

A total of 37 hypertensive patients were enlisted in the study. Among the 37 patients, wakame supplements were given to 19 patients, of whom 1 female patient dropped out of the study. She could not continue visiting our clinic due to personal reasons not related to her health condition. She was therefore excluded form the study and her data were not included, except for safety-related items. Thus, the subjects in this study were fixed as 18 (6 males and 12 females) with an average age of $71.5 \pm 2.5$ years in the wakame group and 18 (6 males and 12 females) with an average age of $70.7 \pm 2.2$ years in the control group.

\section{Comparison of clinical backgrounds between the wakame and the control}

The clinical backgrounds of the patients in the 2 groups are shown in Table 2. No significant differences were seen between the wakame and the control groups regarding sex, age, body height, weight, BMI, mean systolic (SBP) or diastolic blood pressure (DBP). Twenty-six patients were taking anti-hypertensive drugs, primarily calcium channel blockers, $\beta$-blockers, angiotensin converting enzyme (ACE) inhibitors, and diuretics. There was no significant difference in the number of patients on drugs or in the distribution of the drugs used between the 2 groups, although 1 patient was taking diuretics in the wakame group, while none took them in the control group. There were no significant differences in the combined therapy with anti-hypertensive drugs between the 2 groups.

As for the clinical biochemistry, none of the parameters for liver function, renal function, plasma glucose, and serum lipids differed significantly between the 2 groups (Table 3 ).

\section{Ingested amount of wakame and changes in blood pressure of the 2 groups}

Compliance of wakame supplements was estimated from the patient interviews in the wakame group. Six patients ingested all 12 capsules a day, 1 took 9 capsules a day, 2 had 8 capsules a day, 6 took 6 capsules a day, and 3 ingested only 3 capsules a day. Therefore, the average intake of wakame was estimated to be 7.9 capsules or $3.3 \mathrm{~g}$ a day. Changes found in blood pressure after wakame ingestion are shown in Fig. 1. The SBP of the wakame group significantly dropped by $13 \pm$ 
Table 2. Clinical characteristics of the wakame and control groups. ${ }^{1}$

\begin{tabular}{lcc}
\hline & $\begin{array}{c}\text { Wakame group } \\
(n=18)\end{array}$ & $\begin{array}{c}\text { Control group } \\
(n=18)\end{array}$ \\
\hline Male & 6 & 6 \\
Female & 12 & 12 \\
Age (years) & $71.5 \pm 2.5$ & $70.7 \pm 2.2$ \\
Body height $(\mathrm{cm})$ & $156.9 \pm 1.9$ & $157.1 \pm 1.9$ \\
Body weight $(\mathrm{g})$ & $53.7 \pm 1.9$ & $57.0 \pm 2.3$ \\
BMI $\left(\mathrm{kg} / \mathrm{cm}^{2}\right)$ & $21.8 \pm 3.0$ & $23.1 \pm 2.6$ \\
Systolic BP $(\mathrm{mm} \mathrm{Hg})$ & $157.5 \pm 2.3$ & $152.0 \pm 3.0$ \\
Diastolic BP (mm Hg) & $89.9 \pm 2.7$ & $86.8 \pm 1.7$ \\
Heart rate (beat $/ \mathrm{min})$ & $78.4 \pm 3.0$ & $76.8 \pm 2.0$ \\
Kinds of drug used: & & \\
Calcium antagonist & 10 & 9 \\
$\beta$-blocker & 4 & 3 \\
ACE inhibitor & 1 & 0 \\
Diuretics & 5 & 5 \\
Number of drugs used & 9 & 11 \\
$\quad$ None & 4 & 2 \\
One & & \\
Two & &
\end{tabular}

$3 \mathrm{mmHg}(p<0.05)$ after 4 weeks, and by $8 \pm 3 \mathrm{mmHg}(p<0.05)$ after 8 weeks from the baseline; though the SBP of the control group fell slightly, though not significantly, when compared with the baseline value. The difference in SBP between the 2 groups was significant $(p<0.05)$ after the 4 th week.

The DBP of the wakame group was significantly reduced from the baseline by $9 \pm 2 \mathrm{mmHg}(p<0.01)$ after 4 weeks, and by $8 \pm 3 \mathrm{mmHg}(p<0.05)$ after 8 weeks; whereas the change in DBP in the control group was not significant. Differences in DBP changes between the 2 groups were significant both after $4(p<0.01)$ and after 8 weeks $(p<0.05)$. The heart rate in either group did not change significantly during the study period, and did not differ between the 2 groups.

\section{Changes in blood cell counts and biochemical parameters}

Body weight, blood cell counts, and the parameters of liver function, renal function, plasma glucose, and serum lipids did not differ between the baseline levels and the 8-week values except for platelets and free fatty acids in the wakame group, and for uric acid in both groups. However, these changes were within the normal range (Table 3 ).

When the initial serum total cholesterol (TC) levels of the wakame group were subdivided into 2 subgroups hypercholesterolemic (TC $\geqq 5.69 \mathrm{mmol} /$ liter or $220 \mathrm{mg} / \mathrm{dl})$ [11] and normocholesterolemic $(\mathrm{TC}<5.69 \mathrm{mmol} /$ liter or $220 \mathrm{mg} / \mathrm{dl})$, TC decreased significantly $(p<0.01)$ by $0.49 \pm 0.07 \mathrm{mmol} / \mathrm{liter}(19 \pm 3 \mathrm{mg} / \mathrm{dl}, 8 \%)$ after both 4 and 8 weeks of treatment as seen in Fig. 2. In the normocholesterVol. 30, 2001 
Table 3. Comparison of changes in body weight, serum lipids, and other serum biochemical indexes after treatment with wakame and in the control. ${ }^{1}$

\begin{tabular}{|c|c|c|c|c|}
\hline & \multicolumn{2}{|c|}{ Wakame group } & \multicolumn{2}{|c|}{ Control group } \\
\hline & Initial & Final & Initial & Final \\
\hline Pulse (beats/min) & $78.4 \pm 3.0$ & $80.3 \pm 2.9$ & $76.8 \pm 2.0$ & $79.1 \pm 3.4$ \\
\hline Body weight (kg) & $53.7 \pm 1.9$ & $53.5 \pm 2$ & $57.0 \pm 2.3$ & $57.2 \pm 2.3$ \\
\hline TG (mmol/liter) & $1.68 \pm 0.06$ & $1.73 \pm 0.09$ & $1.66 \pm 0.16$ & $1.93 \pm 0.09$ \\
\hline HDL-C (mmol/liter) & $1.46 \pm 0.11$ & $1.41 \pm 0.10$ & $1.37 \pm 0.09$ & $1.40 \pm 0.09$ \\
\hline FFA $(\mu \mathrm{mol} /$ liter $)$ & $366 \pm 53$ & $512 \pm 59 *$ & $552 \pm 75$ & $599 \pm 71$ \\
\hline Glucose (mmol/liter) & $5.29 \pm 0.18$ & $5.08 \pm 0.16$ & $6.31 \pm 0.68$ & $6.10 \pm 0.60$ \\
\hline Sodium (mmol/liter) & $137.8 \pm 0.5$ & $138.8 \pm 0.4$ & $137.3 \pm 0.7$ & $138.4 \pm 0.4$ \\
\hline Potassium (mmol/liter) & $4.0 \pm 0.1$ & $4.1 \pm 0.1$ & $4.0 \pm 0.1$ & $4.1 \pm 0.1$ \\
\hline Chloride (mmol/liter) & $100.1 \pm 0.7$ & $100.9 \pm 0.5$ & $99.9 \pm 0.8$ & $100.2 \pm 0.6$ \\
\hline BUN (mmol/liter) & $6.39 \pm 0.43$ & $6.43 \pm 0.50$ & $5.43 \pm 0.43$ & $5.43 \pm 0.39$ \\
\hline Uric acid $(\mu \mathrm{mol} /$ liter $)$ & $363 \pm 18$ & $351 \pm 24^{*}$ & $309 \pm 24$ & $321 \pm 24^{*}$ \\
\hline Creatinine ( $\mu \mathrm{mol} /$ liter $)$ & $88.4 \pm 8.8$ & $88.4 \pm 8.8$ & $88.4 \pm 8.8$ & $88.4 \pm 8.8$ \\
\hline GOT (IU/liter) & $23.0 \pm 1.9$ & $40.9 \pm 17.7$ & $30.8 \pm 4.1$ & $29.1 \pm 3.7$ \\
\hline GPT (IU/liter) & $18.9 \pm 2.7$ & $36.6 \pm 17.2$ & $23.9 \pm 3.8$ & $22.7 \pm 3.5$ \\
\hline$\gamma$-GTP (IU/liter) & $31.7 \pm 4.7$ & $30.5 \pm 4.3$ & $72.8 \pm 30.2$ & $65.0 \pm 26.5$ \\
\hline $\mathrm{Hb}(\mathrm{g} /$ liter $)$ & $136 \pm 4$ & $133 \pm 4$ & $139 \pm 4$ & $140 \pm 5$ \\
\hline RBC $\left(\times 10^{12} /\right.$ liter $)$ & $4.3 \pm 0.1$ & $4.3 \pm 0.2$ & $4.3 \pm 0.1$ & $4.4 \pm 0.1$ \\
\hline WBC $\left(\times 10^{9} /\right.$ liter $)$ & $6.0 \pm 0.4$ & $6.3 \pm 0.4$ & $6.1 \pm 0.4$ & $6.2 \pm 0.4$ \\
\hline Platelets $\left(\times 10^{10} /\right.$ liter $)$ & $24.5 \pm 1.5$ & $22.9 \pm 1.5^{*}$ & $23.5 \pm 2.0$ & $22.4 \pm 1.5$ \\
\hline
\end{tabular}

${ }^{1}$ Mean \pm SE. TG, triacylglycerol; HDL-C, HDL-cholesterol; FFA, free fatty acid; BUN, blood urea nitrogen; GOT, glutamic oxaloacetic transaminase; GPT, glutamic pyruvic transaminase; $\gamma$-GTP, $\gamma$-glutamyltranspeptidase; $\mathrm{Hb}$, hemoglobin; RBC, red blood cell; WBC, white blood cell. *Significantly different from the baseline, $p<0.05$.
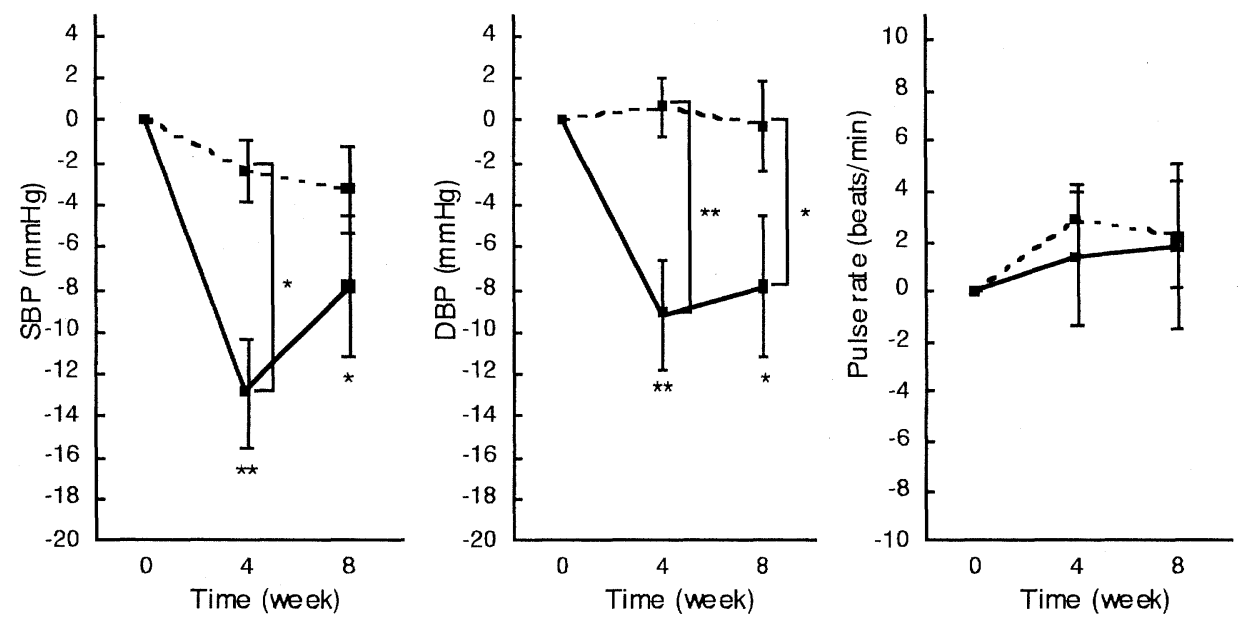

Fig. 1. Changes in systolic blood pressure (SBP), diastolic blood pressure (DBP), and pulse rate of subjects during 8 week treatment with wakame (line) and control (dotted line). Mean $\pm \mathrm{SE}$; significantly different from baseline value: $* p<0.05, * * p<0.01$, brackets show significant difference from control: ${ }^{*} p<0.05, * * p<0.01$. 


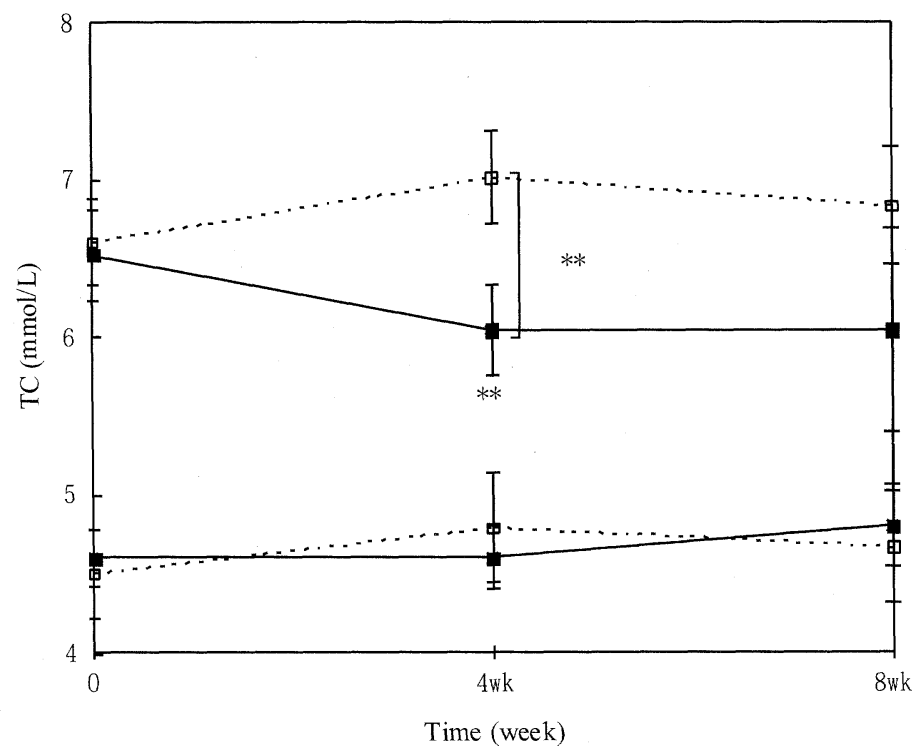

Fig. 2. Changes in total cholesterol (TC), during treatment for 8 weeks with wakame line) and control ( $\square$, dotted line). Mean \pm SE; significantly different baseline value: ${ }^{* *} p<0.01$, brackets show significant difference from control; ${ }^{* *} p<0.01$.

olemic subgroup, there was no such reduction in total cholesterol.

Side effects in the 2 groups

Adverse symptoms in the wakame group during the 8 weeks of the study period included 2 cases of indigestion ( 1 male and 1 female) and 1 case of diarrhea ( 1 male). None of these symptoms were serious, and they disappeared after a short time without specific treatment. The other 4 patients in the wakame group reported improvement in their chronic constipation. In the control group, no side effects were reported.

\section{DISCUSSION}

In this study, we administered desalted, powdered wakame to hypertensive out-patients, whose blood pressure occasionally exceed $150 \mathrm{mmHg}$ SBP and/or 90 $\mathrm{mmHg} \mathrm{DBP}$, despite their being under salt restriction and on previously prescribed anti-hypertensive medication, and monitored changes in blood pressure and clinical chemistry parameters for 8 weeks. After the ingestion of wakame, the blood pressure decreased significantly by $13 \pm 3 \mathrm{mmHg}$ for SBP, and by $9 \pm 2$ $\mathrm{mmHg}$ for DBP after 4 weeks, and by $8 \pm 3 \mathrm{mmHg}$ for DBP and by $8 \pm 3 \mathrm{mmHg}$ in SBP after 8 weeks. Though the effects of wakame were greater after 4 weeks than after 8 weeks, the decrease in blood pressure after 8 weeks was still statistically 
significant when compared with the baseline level. The effect of wakame ingestion after 8 weeks falls into the category of "moderate improvement" in the evaluation criteria for the development of anti-hypertensive drugs [12], which define moderate improvements as a drop of 10 to $19 \mathrm{mmHg}$ systolic, and/or 5 to $9 \mathrm{mmHg}$ diastolic. Krotkiewski et al. reported that alginate decreased mean blood pressure significantly with a daily dose of $12 \mathrm{~g}$ or $24 \mathrm{~g}$ after 4 weeks, but not with $6 \mathrm{~g}$ a day [2]. Since the average daily dose of wakame was $3.3 \mathrm{~g}$ in this study, the dose may have been a little too low. However, the wakame preparation is not a drug but a dietary regimen. Therefore, this modest effect of wakame seems to be adequate for the dietary regimen in the treatment of hypertension.

In this study, we could not prepare a placebo for the wakame because of the unique characteristics of wakame, which include a fishy smell, slippery and fibrinous texture, and water absorbent property. Therefore, Japanese could easily discern wakame from a placebo by judging the smell, color, taste or texture of the capsule contents. Without a placebo, however, the control group showed a slight fall in blood pressure ( $3 \mathrm{mmHg}$ in SBP and $0.3 \mathrm{mmHg}$ in DBP). This type of response in the control group was reported with non-drug treatments such as sour milk (4 mmHg in SBP and $1 \mathrm{mmHg}$ in DBP [5]), fish oil $(2 \mathrm{mmHg}$ in SBP and 1 $\mathrm{mmHg}$ in DBP [8]), and magnesium supplementation $(-0.3 \mathrm{mmHg}$ in SBP and $0.2 \mathrm{mmHg}$ in DBP [13]). The results in this study indicate that wakame supplementation will be of significant benefit in the non-drug treatment of hypertension.

As shown in Table 1, dry wakame ( $100 \mathrm{~g})$ contains $53 \mathrm{~g}$ of dietary fiber, whose main constituents are alginates $[14,15]$. Alginates are indigestible carbohydrates that act as typical dietary fiber [16]. Dietary fibers, in general, are known to exert a wide variety of physiological actions, reducing hypertension $[1,2,17]$, hypercholesterolemia [3], impaired glucose intolerance and insulin [4], intestinal flora $[18,19]$, and the risk of colon cancers [20].

Studies in vitro showed that alginates act as an ion exchanger in liquids, absorbing sodium ions from and releasing potassium ions into liquid media [21, 22]. Yamori indicated that the effects of alginates on hypertension in SHRSP were caused by alginates increasing fecal excretion of sodium, while decreasing urinary sodium excretion [1]. In addition to alginates, wakame contains large quantities of minerals including calcium and magnesium (Table 1). These minerals may play a role in the reduction of blood pressure in hypertensive subjects. There are epidemiological studies showing that there was an inverse correlation between the intake of calcium and magnesium and blood pressure [23]. However, wakame contained only approx. $1 \%$ calcium and magnesium by weight, and this amount may be too small for the quantity to be effective in blood pressure reduction [13, $24,25]$.

Another possible reason for the blood pressure-lowering effect of wakame may be fucosterol, which was isolated from brown seaweed [26, 27]. Though the physiological mechanism of fucosterol in vivo is not yet clear, there are reports that fucosterol reduced ACE activities on endothelial cells by inhibiting the synthesis 
of glucocorticoid receptors that regulate ACE activities [28]. Also, fucosterol was reported to enhance plasminogen activator inhibitor- 1 on endothelial cells [29, $30]$.

More recently, peptides having ACE-inhibiting activity were isolated from a peptic digestion of wakame. Oral administration of these peptides decreased the elevated blood pressure of SHR rats [31]. The presence of these ACE inhibitory peptides in a peptic digest of wakame suggests that they could be responsible for the observed blood pressure-lowering effects of wakame.

Therefore, the blood pressure-lowering effect of wakame seems to be attributed to the synergistic action of alginates, minerals, fucosterol, and peptides having ACE-inhibiting activity or some unknown component(s). Similar clinical effects of wakame were reported by Nara et al. [32].

Besides blood pressure, wakame reduced elevated serum cholesterol by an average of $0.49 \pm 0.07 \mathrm{mmol} /$ liter $(19 \pm 3 \mathrm{mg} / \mathrm{dl}, 8 \%)$ in 8 weeks. This cholesterollowering action of wakame has been shown in animal experiments [33, 34]. Wakame is considered to accelerate excretion of cholesterol in the feces [34]. Thus, wakame may inhibit the absorption and reabsorption of cholesterol in the intestine and consequently reduce serum cholesterol levels.

Some anti-hypertensive drugs such as $\beta$-blockers and diuretics are known to elevate serum cholesterol and triacylglycerides [35-37]. When hypertensive patients are treated with these drugs, wakame may be of help in reducing the unwanted elevation in serum lipids caused by them. This reduction was shown in the rat as being due to changes in enzyme activities involved in fatty acid metabolism in the liver [38].

These results indicate that ingestion of wakame has a beneficial effect as a dietary regimen in the treatment of hypertension with or without hypercholesterolemia. The side effects are minimal and not serious. Once the mechanism of wakame action has been clarified, the use of wakame may be further promoted as a supplemental remedy.

\section{REFERENCES}

1. Yamori, Y., Nara, Y., Tsubouchi, T., Sogawa, Y., Ikeda, K., and Horie, R. (1986): Dietary prevention of stroke and its mechanisms in Stroke-Prone spontaneously hypertension rats-preventive effect of dietary fibre and palmitoleic acid. J. Hypertens., 4, Suppl. 3, S449S452.

2. Krotkiewski, M., Aurell, M., Holm, G., Grimby, G., and Szczepanik, J. (1991): Effects of a sodium-potassium ion-exchanging seaweed preparation in mild hypertension. Am. $J$. Hypertens., 4, 483-488.

3. Tsuji, K., Oshima, S., Matsuzaki, E., Nakamura, A., Innami, S., Tezuka, T., and Suzuki, S. (1968): Effect of polysaccharides on cholesterol metabolism (Part 1). Eiyogaku Zasshi, 26, $113-122$.

4. Torsdottir, I., Alpsten, M., Holm, G., Sandberg, A., and Tolli, J. (1991): A small dose of soluble alginate-fiber affects postprandial glycemia and gastric emptying in humans with diabetes. J. Nutr., 121, 795-799.

5. Hata, Y., Yamamoto, M., Ohni, M., Nakajima, K., Nakamura, Y., and Takano, T. (1996):

Vol. 30, 2001 
A placebo controlled study of the effect of sour milk on blood pressure in hypertensive subjects. Am. J. Clin. Nutr., 64, 767-771.

6. Steiner, M., Khan, A.H., Holbert, D., and Lin, R.I. (1996): A double-blind cross over study in moderately hypercholesterolemic men that compared the effect of aged garlic extract and placebo administration on blood lipids. Am. J. Clin. Nutr., 64, 866-870.

7. Nakajima, K., Hata, Y., Osono, Y., Hamura, M., Kobayashi, S., and Watanuki, M. (1995): Antihypertensive effect of extracts of Lactobacillus casei in patients with hypertension. $J$. Clin. Biochem. Nutr., 8, 181-187.

8. Sharpe, S.J., Gamble, G.D., and Shrpe, D.N. (1994): Cholesterol-lowering and blood pressure effects of immune milk. Am. J. Clin. Nutr., 59, 929-934.

9. Morris, M.C., Taylor, J.O., Stampfer, M.J., Rosner, B., and Sacks, F.M. (1993): The effect of fish oil on blood pressure in mild hypertensive subjects: A randomized crossover trial. Am. J. Clin. Nutr., 57, 59-64.

10. Moran, J.P., Cohen, L., and Greene, J.M. (1993): Plasma ascorbic acid concentrations relate inversely to blood pressure in human subjects. Am. J. Clin. Nutr., 57, 213-217.

11. Japan Atherosclerosis Society (1997): Investigation Committee of Guideline for Diagnosis and Treatment of Hyperlipidemia in adults. J. Jpn. Atherosclerosis Soc., 25, 1-34.

12. Japan Hypertension Society Working Group (Kaneko, Y. et al., 1994): Guideline for clinical evaluation of drugs in research and development, in Handbook of Guidelines for Development of New Drugs, Yakugyo Jiho, Tokyo, pp. 222-239.

13. Witteman, J.C.M., Grobbee, D.E., Derkx, F.H.M., Bouillon, R., Brujin, A.M., and Hofman, A. (1994): Reduction of blood pressure with oral magnesium supplementation in women with mild to moderate hypertension. Am. J. Clin. Nutr., 60, 129-135.

14. Lahate, M. (1991): Marine algae as sources of fibre: determination of soluble and insoluble dietary fiber contents in some "sea vegetable." J. Sci. Food Agric., 54, 587-594.

15. Sakurai, Y. (1994): Alginic acid, in General Food Dictionary, 6th ed., Dobun Shoin, Tokyo, p. 39.

16. Humphrey, E.R., and Triffitt, J.T. (1968): Absorption by the rat of alginate labeled with carbon-14. Nature, 219, 1172-1173.

17. Mitchell, W.D., and Eastwood, M.A. (1978): Dietary fiber and colon function, in Fiber in Human Nutrition, ed. by Spiller, G.A., and Amen, R.J., Plenum Press, New York, pp. 185206.

18. Mitsuoka, T. (1994): Current status and future prospects of studies on intestinal flora and dietary factors, in Intestinal Flora and Dietary Factors, ed. by Mitsuoka, T., Gakkai Shuppan Center, Tokyo, pp. 1-14.

19. Eastwood, M.A., Eastwood, J., and Wan, M. (1978): Epidemiology of bowel disease, in Fiber in Human Nutrition, ed. by Spiller, G.A., and Amen, R.J., Plenum Press, New York, pp. $207-240$.

20. Story, J.A., Kritchevsky, D., and Eastwood, M.A. (1979): Dietary fibre-bile acid interactions, in Dietary Fiber-Chemistry and Nutrition, ed. by Inglett, G.E., and Falkenag, S.I., Academic Press, New York, pp. 49-55.

21. Kloareg, G., Dermarty, M., and Mabean, S. (1987): Ion-exchange properties of isolated cell walls of brown algae. J. Exp. Bot., 38, 1652-1662.

22. Tsuji, K., Tsuji, E., Nakagawa, Y., and Suzuki, S. (1988): Effects of Na-binding capacity of dietary fibers on blood pressure in spontaneously hypertensive rats. J. Home Econom. Jpn., 39, $187-195$.

23. Harlan, W.R., and Harlan, L.C. (1995): Blood pressure and calcium and magnecium intake, in Hypertension-Pathophysiology, Diagnosis and Management, 2nd ed., ed. by Laragh, J.H., and Briwn, B.M., Raven Press, New York, pp. 1143-1154.

24. McCarron, D.A., Morris, C.D., and Cole, C. (1982): Dietary calcium in human hypertension, Science, 217, 267-269.

25. McCarron, D.A., and Morris, C.D. (1985): Blood pressure response to oral calcium in persons with mild to moderate hypertension. Ann. Int. Med., 103, 825-831.

26. Oka, Y., Kiriyama, S., and Toshida, A. (1973): Sterol composition of fruits, fungi, marine 
algae and tea, coffee and cocoa. Jpn. Soc. Food Nutr., 26, 317-327.

27. Ilias, A.M., Connor, W.E., Lin, D.S., and Ahmad, M.U. (1985): Sterol composition of some seaweed. Fett Seifen Anstrichm., 87, 345-346.

28. Hagiwara, H., Wakita, K., Inada, Y., and Hirose, S. (1986): Fucosterol decreases angiotensin converting enzyme levels with reduction of glucocorticoid receptors in endothelial cells. Biochem. Biophys. Res. Commun., 139, 348-352.

29. Hagiwara, H., Shimonaka, M., Morisaki, M., Ikekawa, N., and Inada, Y. (1984): Sitosterol stimulative production of plasminogen activator in cultured endothelial cells from bovine carotid artery. Thromb. Res., 33, 363-370.

30. Shimonaka, M., Hagiwara, H., Kojima, S., and Inada, Y. (1984): Successive study on the production of plasminogen activator in cultured endothelial cells by phytosterol. Thromb. Res., 36, 217-222.

31. Suetsuna, K., and Nakano, T. (2000): Identification of an antihypertensive peptide from peptic digest of wakame (Undaria pinnantifida). J. Nutr. Biochem., 11, 450-454.

32. Nara, Y., Miura, A., Moriguchi, H., Mpriguchi, Y., and Yamori, Y. (1997): Dietary treatment. Jpn. Circ. J., 61, Suppl. 1, 66.

33. Ren, D., Noda, H., Amano, H., Nishino, T., and Nishizawa, K. (1994): Study on antihypertensive and antihyperlipidemic effects of marine algae. Fish. Sci., 60, 83-88.

34. Tani, M., Stoh, M., Tani, Y., and Hayasaki, K. (1995): Influence of cholesterol metabolism on wakame in rats. Nippon Nogei kagaku Kaishi, 69, Suppl., 153(abs).

35. Ames, R.P. (1983): Negative effects of diuretics drugs on metabolic risk factors for coronary heart disease. Am. J. Cardiol., 51, 632-638.

36. Nakamura, H. (1987): Effects of antihypertensive drugs on plasma lipids. Am. J. Cardiol., 60, 24E-28E.

37. Hollenberg, N.K. (1990): Management of hypertension: Considerations involving cardiovascular risk reduction. J. Cardiovasc. Pharmacol., 15, Suppl., S37-S38.

38. Murata, M., Ishihara, K., and Saito, H. (1999): Hepatic fatty acid oxidation enzyme activities are stimulated in rats fed the brown seaweed, Undaria piannatifida (wakame). J. Nutr., 129, 146-151. 